\title{
The physics classroom as a space for empowerment
}

\author{
Khadíjih Mitchell-Polka \\ School of Education, University of Colorado Boulder, 249 UCB, Boulder, Colorado, 80309 \\ William E. Lindsay, Julian Stenzel Martins, and Valerie K. Otero \\ School of Education, University of Colorado Boulder, 249 UCB, Boulder, Colorado, 80309
}

This paper reports on initial work to develop a framework on empowerment through physics education. Theories from multiple disciplines and research in physics education research informed this framework, alongside leveraging student reflections from four university physics courses for non-science majors. The resulting framework contains five dimensions of empowerment through physics: academic, social, political, emotional, and epistemic. This paper outlines and give examples of students' written work where markers of these dimensions manifested. Self-advocacy was identified as a thread that connects each dimension and opportunities for future research on empowerment in the physics classroom are discussed. 


\section{INTRODUCTION}

Many physicists consider themselves to be seekers of truth regarding the natural world, and although engaging in the process of developing physics understanding can be empowering, traditional physics teaching practices afford few opportunities for students to experience the true nature of science [1]. We view empowering experiences as those that help individuals gain control over matters of importance within their lives, exert influence within their communities, and advocate for their needs [2-5]. As Millikan and other physicists concerned with education have argued for over 100 years [1,6], physics education has the potential to encourage such empowerment if physics is taught in a way that is readily understood, accessible to diverse student groups, and encourages student engagement in the practices of science. According to reports on teacher preparation and practice, physics classrooms have rarely followed these guidelines and have usually operated as a disempowering space for many students [7-10]. Osborne [7] connected this tendency for disempowerment to a deeply ingrained belief regarding the need for rigorous apprenticeship into physics. Students who survived this apprenticeship were accepted into a community of physicists, while those who did not were perceived as lacking the necessary aptitude, fortitude, or disposition to become a physicist. These sorting mechanisms have positioned physics as an elite discipline that only a select group of individuals have the capacity to do [11-13].

Historically, there have been limited opportunities for physics students to advocate for their needs, exert influence in the classroom, or participant in other potentially empowering experiences. Thus, providing such empowering experiences may be a promising path forward for improving physics education. However, researchers have yet to surface a framework that characterizes what empowerment through physics might look like, and what pedagogical approaches might foster feelings of empowerment within a physics classroom. Thus, this paper reports on initial work to develop such a framework, which includes potential dimensions of physics empowerment and markers of what empowerment may look like within each dimension. This framework was developed through a synthesis of empowerment literature, focus groups with experts in physics education research, and reflections from students who may have experienced empowerment in an introductory physics course. Ultimately, it is our hope that developing this framework will provide physics educators with a blueprint for encouraging diverse forms of empowerment through physics education. We explore the following research questions:

1. How is the construct of empowerment and its associated dimensions conceptualized across the literature?

2. What are some markers of potential dimensions of empowerment in the physics classroom?

\section{EMPOWERMENT}

The construct of empowerment initially arose out of the Mexican-American war of 1848 , but was more notably recognized in the 1960s during the Chicano/Chicana civil rights movement [14] and the Black Power movement [2]. During these movements, individuals were striving to disassemble inequitable distributions of power by fighting back against oppression and acting on issues concerning their communities. The grassroots nature of these movements paved the way for a bottom-up approach to empowerment to be researched in various fields including psychology, feminism, social work, and education [2]. While there was much variation in how empowerment was conceptualized across these traditions, empowerment was repeatedly described as a means to help individuals gain control over matters of importance within their lives, exert influence within their communities, and advocate for their needs [2-5]. With diverse beliefs around what it meant to become empowered, Perkins \& Zimmerman [15] cautioned researchers not to stick firmly to one definition, as it is a multidimensional construct that cannot be simply defined. Further, researchers must be careful when generalizing methods of empowerment, as what works to empower one individual may not work for all. Finally, empowerment has been criticized for its increasing appropriation as a morally unimpeachable buzzword to portray an inherently positive outcome, rather than a contested and trying process dependent on the individual $[16,2]$.

Zimmerman [4] proposed a multidimensional framework of psychological empowerment including intrapersonal, interactional, and behavioral dimensions of empowerment. The intrapersonal dimension encompassed the impact that certain activities had over an individual's ability to exert influence in their community. The interactional dimension included an individual's awareness of their sociopolitical environment and how they perceived their communities. Lastly, behavioral empowerment consisted of actions that directly affected an individual's personal outcomes and their feelings about themselves [15, 4].

More specific to science education, Dimick [17] proposed a framework of empowerment in the science classroom that initially included social, academic, and political dimensions, and was later amended to include a dimension of emotional empowerment [18]. Social empowerment referred to the cultivation of safe, supportive, nondiscriminatory, and antioppressive relationships that are formed between teachers and students [17, 19-20]. Academic empowerment was encouraged when students were taught in a way that built from their prior experiences and provided opportunities to gain useful knowledge and skills [17]. Political empowerment occurred when the teaching and learning methods used in the classroom helped mobilize students to work toward a more socially just society. Lastly, emotional empowerment was made possible by building classroom relationships that were nurtured with love and 
respect [18]. This previous work, alongside focus groups with experts in physics education and student reflections on their classroom experiences, informed the development of an empowerment through physics education framework.

\section{APPROACH TO FRAMEWORK DEVELOPMENT}

The creation of the empowerment through physics framework began in the fall of 2018 and was iteratively refined through spring 2020. This paper's first author drafted an initial framework by drawing from empowerment literature, conversations she had with faculty advisors, and her own experiences with empowerment when learning physics and participating in physics research as an undergraduate. The initial framework was then used as a conceptual guide for a semester-long pilot study on empowerment in a local high school classroom using lesson materials from the Physics through Evidence, Empowerment through Reasoning (PEER Physics) curricular suite. The PEER Physics pedagogical approach is described later in greater detail. The first author took ethnographic field notes during weekly participant observations focused on identifying and describing the experiences of students who displayed markers of empowerment and disempowerment in the classroom. She also conducted and transcribed four $\sim 30$ minute interviews with high school students, where she directly inquired about the construct of empowerment and if/how students had experienced empowerment or disempowerment when learning physics. She then deductively coded collected data using the initial empowerment framework as a coding guide.

The findings of this pilot study were used to produce a second iteration of the framework, which was then shared with physics education research experts. During structured focus groups, experts discussed the framework in reference to their own experiences in physics education and provided feedback. These discussions were used to further develop the framework into its current dimensions of academic, social, political, emotional, and epistemic empowerment.

As a final step, we leveraged student data from four nonscience major undergraduate classes at a large research university using the PEER Physics curricular approach. In PEER Physics courses, students work in groups to induce physics principles by completing experimental activities and routinely engaging in small-group and whole-class discussions to come to consensus on experimental results and conclusions. Student work focuses on articulating how experimental evidence supports model-based claims related to physical phenomena. Students spend class periods working in small groups, engaging in experiments, and responding to scaffolded conceptual physics questions that strategically omit formalized physics principles. The purpose of this pedagogical approach is for epistemic authority to be shifted from teacher and textbook to evidence and community consensus, and epistemic agency is shifted from the teacher to the student. Indeed, no traditional textbook is used in this course.

Undergraduate students submitted short essay reflections in which they responded to open-ended prompts related to the PEER Physics pedagogical approach and their learning experiences. These assignments were graded on completion and students were urged to voice their honest, and sometimes critical, thoughts. We used reflections to identify potential markers of physics empowerment dimensions as described in students' own words. Each of this paper's authors coded a sample of 28 responses from consenting students using the current iteration of the framework as a deductive guide. We then shared our coding results, adjudicated about differences between codes, and updated the framework.

\section{DIMENSIONS OF PHYSICS EMPOWERMENT}

We currently understand empowerment encouraged through physics education as encompassing five dimensions. The first three dimensions, Academic relationship to physics, Social interactions and relationships encouraged through physics, and Political relationship with physics and the physics community were influenced by Zimmerman's [4] conceptualization of intrapersonal, interactional, and behavioral dimensions of empowerment, alongside Dimick's [17] conceptualization of academic, social, and political empowerment in science classrooms. The fourth dimension, Emotional relationship with physics was influenced by Tolbert, Rodriguez and Schindel's [18] understanding of emotional empowerment and Oyler and Becker's [21] argument for shared authority and vulnerability.

The fifth dimension, Epistemic agency in relation to physics, was not referenced in prior empowerment work but surfaced during focus groups, our analysis of student reflections, and our prior research [22]. This dimension may have been tied to the PEER Physics pedagogical approach, where students induce principles. In addition, as physics is a discipline with clear epistemological commitments and associated phenomena that can be easily investigated in the classroom, the study of physics may be especially conducive to promoting empowerment through epistemic agency.

\section{A. Academic relationship to physics}

Empowerment through an academic relationship with physics may be made possible when students are provided space to develop tools to experience academic success. This occurs in a formal sense by demonstrating aptitude with disciplinary physics knowledge on graded course assignments or informally through moments of feeling successful at understanding phenomena during in-class activities. This may be made possible when students have opportunities to build on their prior knowledge to develop physics conceptual understanding, are able to connect this conceptual understanding to numerical representations, and/or feel successful in applying the epistemic commitments of physics to investigations of natural 
phenomena. The following is an example of a student quote that we feel may exemplify markers of this dimension:

"I am a visual learner. When we do experiments in class where I can clearly see why certain science ideas work certain ways, I have an easier time remembering the concept... We looked at the [bathroom] scales pressing up against each other... The scales were always even... This made it super clear to me that objects exert the same amount of force on each other. It is also easy for me to grasp concepts with equations. When we learned about how $\boldsymbol{F}=\boldsymbol{F}$ and $M a=m A$, it helped me understand that objects with greater masses will have less acceleration, and objects with lesser masses will have a greater acceleration."

This student explained how in-class experimentation supported them by providing a visual representation of physics phenomena. They also expressed a sense of clarity and ease with how course structures facilitated the use of conceptual knowledge to explain natural phenomena and helped them connect conceptual understanding to equations.

\section{B. Social interactions and relationships encouraged through physics}

Social empowerment may occur when students feel they are a part of a supportive community with a shared understanding of norms and expectations, interact with others to make sense of phenomena, and feel comfortable and capable of sharing their physics knowledge. In addition, students may leverage the distributed expertise of community members to negotiate tentative ideas. These interactions may help students recognize that they are not alone in the struggle to learn and produce physics knowledge. The following quote exemplifies these markers of the social empowerment dimension:

"I think that many of the exercises that we do as a group in class are helpful in the way that they make us work together and as a result we become better at working with one another. We get to know one another better as the class goes on through talking as a group and working through the problems together. That is to say that we are able to understand how our group members' minds understand the physics of each issue, and as a result we can more effectively bounce ideas off of each other."

This student found that interacting with others in a classroom with shared norms and expectations was helpful for working through problems. They also described belonging to a community that was comfortable "bouncing ideas off each other" and the benefit of hearing multiple ideas about physics. As students got to "know one another better", there were increased markers of social empowerment.

\section{Political relationship with physics and the physics community}

Empowerment through a political relationship with physics and the physics community may be made possible by disrupting normative conceptions of who can do physics, and taking action to change the power structures that exist within physics and physics education in an effort to broaden the perspective of what it means to learn physics. This may be possible when students understand the dynamics of power and privilege within physics, recognize systemic and/or personal injustices, and are mobilized to create change in the world of science. Changing perceptions of what it means to learn and do physics may ultimately allow for physics education to be more accessible to a broader range of individuals. The following is an excerpt from a student majoring in education who was fulfilling practicum requirements by taking the PEER Physics course:

"I think it's really a shame how lots of science classes are still incredibly lecture based. They rely on students engaging in memorization and not in active understanding of the material. Because of this, I think students either do not like science... Or they find science to be incredibly challenging because there is a barrier to entry. Students who are bad at memorization will be bad at science class in this model... Students who engage in this idea of doing science to learn science will be better able to understand the material and will have a lower barrier to entry as they are actively coming up with the ideas themselves. Through this model in PEER Physics of not being able to say something is true until we have done/collected the data ourselves, we are better understanding both the material and also the process of science... Overall, I think that the experimentation and model based claims that PEER Physics provides allows for students to more readily engage and learn the material better than a traditional lecture based course."

Here, the student challenged normative perspectives of how science should be taught and argued that these perspectives cause a "barrier to entry" for many students that lack skills such as memorization. They further argued for broadening the perspective of what it means to learn physics, moving towards "doing science to learn science" by leveraging the use of materials and active knowledge production to make physics more accessible.

\section{Emotional relationship with physics}

Students may have the opportunity to become empowered through their emotional relationship with physics when they are in an environment with supportive mentors, are able to overcome fears and feelings of vulnerability associated with learning physics, and are provided the opportunity to increase their feelings of selfefficacy when learning and discussing physics phenomena. This dimension also incorporates feelings of successful participation in scientific sensemaking and persevering through moments that could be perceived as failures. A student reported such experiences in the following reflection:

"This course has provided a very safe and helpful learning environment for me... In a typical large lecture environment, I am usually too scared and embarrassed to ask questions to clarify when things get hazy, which leaves me 
doing poorly in the classes and feeling more embarrassed and unintelligent. But being put in a class that is all about working with others has really helped me learn the material. Since this whole course basically forces me to ask my peers around me for their input and ideas, it creates a more open environment for me to ask my own questions when I am stuck on something... This course has also lifted my spirits about the science subject in general."

This student perceived their classroom as a "safe and helpful" environment that fostered a more welcoming and open experience to learning physics. Further, they alluded to an increased sense of self-efficacy due to their experiences working with others. Although they were "basically forced" to interact with their peers, these interactions supported them in comfortably voicing tentative thoughts.

\section{E. Epistemic agency in relation to physics}

Epistemic empowerment may occur when students take responsibility for their own learning and exhibit autonomy when making sense of physics concepts. Such empowerment may be encouraged by engaging in scientific practices and leveraging the epistemic tools of the physics community. In addition, students experiencing epistemic empowerment may be comfortable learning physics in a variety of ways. A reflection from a student touched on these markers:

"I feel as if I have more time and more ways to solidify my ideas based on evidence I and my group saw, felt, and made. For example, I really enjoy having time to think about the issue at hand individually, before explaining to my group my reasoning. By explaining our group ideas to the group next to us, allows us to grow another type of confidence in our answer before explaining it to the class. Questioning your own ideas, I think, is more powerful than having an expert question your ideas.",

The opportunity to formulate and defend the reasoning behind evidence-based ideas helped this student become more confident as a producer of physics knowledge. "Questioning" their own ideas before expert evaluation was also described as a "powerful" learning experience.

\section{F. Empowerment as a dynamic construct}

We posit that each of the above dimensions constitutes a potential form of empowerment through physics learning. These dimensions lend themselves to the development of a broader empowerment framework intended to be flexible enough to characterize students' multiple forms of experiencing empowerment. This flexibility is important, as we agree with prior empowerment research that conceptualizes the empowerment process as one that is not fixed. We currently view empowerment as a dynamic construct whose characterization in a given setting depends on how individuals embedded in the local process of empowerment describe their own experience and ground that experience within their own lives [4]. Therefore, our conjecture is that even though multiple forms of physics empowerment may emerge across members of a learning environment, a decision regarding whether or not a given individual is or is not empowered should not depend on whether there is evidence of all the empowerment dimensions we have described. Rather, each dimension is conceptualized with possible markers of an overall empowerment process, one that is influenced by the structures and objectives of the learning environment, and one whose impacts on individuals are inevitably varied.

\section{CONCLUSIONS}

This paper represents a first step in developing a framework that describes what dimensions of empowerment could look like within a physics classroom. Drawing from relevant literature, expert opinions, and student reflections, we described and gave examples of academic, social, political, emotional, and epistemic dimensions of empowerment through physics education. Given the contextual nature of empowerment, we contend that a framework which specifically delineates markers of empowerment in the physics classroom could be an essential tool for designing and enacting empowering physics pedagogies. Such pedagogies have the potential to broaden the perspective of who can do physics and create pathways to make physics education more accessible.

In terms of future work, prior empowerment research has described self-advocacy as a related, but separate, concept to empowerment $[2,3]$. Our data showcased that in a physics learning environment, an individual's belief that they can successfully advocate for their needs relates to whether they feel that they can voice concerns, struggles, and thoughts; whether they have confidence in their capabilities; and whether they feel heard by those to whom they advocate are important markers of empowerment. Following these findings, we hypothesize that self-advocacy is a common thread that weaves our framework dimensions together; however, further research is needed to test this hypothesis.

Additionally, in discussions of empowerment, it is important to recognize the power dynamics present within physics education and the field of physics. Although the data we used in this study was not conducive to establishing claims about power dynamics beyond the political dimension, future research efforts should attend to this key component of empowerment. We have designed reflection prompts that more specifically focus on power and hope to report more on this in later research. Ultimately, more work needs to be done to better understand how empowerment may occur within varied course structures and what effect empowerment has on students' experiences learning physics. Establishing a framework of empowerment in the physics classroom is a crucial step forward in achieving these aims.

\section{ACKNOWLEDGEMENTS}

The authors wish to thank participating students, the CU Boulder PER group, and NSF Grant \#1340083. 
[1] V. K. Otero and D. E. Meltzer, The past and future of physics education reform. Phys. Today, 75, 50 (2017).

[2] A-E. Calvès, Empowerment: the history of a key concept in contemporary development discourse. Revue Tiers Monde, 200, 735 (2009).

[3] L. B. Cattaneo, and A. R. Chapman, The Process of Empowerment: A Model for Use in Research and Practice. American Psychologist, 65, 646 (2010).

[4] M. A. Zimmerman, Psychological empowerment: Issues and illustrations. American Journal of Community Psychology, 23, 581 (1995).

[5] J. Rappaport, Terms of empowerment/exemplars of prevention: Toward a theory for community psychology. American Journal of Community Psychology, 15, 121 (1987).

[6] R.A. Millikan, Science in the secondary school. School Science and Mathematics, 17, 379 (1917).

[7] J. Osborne, Sacred cows in physics - towards a redefinition of physics education. Phys. Education, 25, 189 (1990).

[8] P. Mulhall and R. Gunstone, Views About learning physics held by physics teachers with differing approaches to teaching physics. Journal of Science Teacher Education, 23, 429 (2012).

[9] D.E. Meltzer, M. Plisch, and S. Vokos, Transforming the Preparation of Physics Teachers: A Call to Action. A Report by the Task Force on Teacher Education in Physics (T-TEP). Am. Phys. Soc., (2012).

[10] V. K. Otero, Nationally scaled model for leveraging course transformations with physics teacher preparation, in Recruiting and Educating Future Physics Teachers: Case Studies and Effective Practices, edited by C. Sandifer and E. Brewe (American Physical Society, College Park, MD). Am. Phys. Soc., 107 (2015).

[11] N. Dasgupta, How stereotypes impact women in physics. Phys., 9 (2016).

[12] S. Hyater-Adams, C. Fracchiolla, N.D. Finkelstein, and K. Hinko, Understanding connections between physics and racial identities through recognition and relational resources. $\underline{\text { PERC }}$ Proceedings, 164 (2016).

[13] S. Hyater-Adams, C. Fracchiolla, N.D. Finkelstein, and K. Hinko, Critical look at physics identity: An operationalized framework for examining race and physics identity. Phys. Rev. Physics Education Research, 14 (2018).

[14] R. Rodriguez, The Origins and History of the Chicano Movement. Julian Samora Research Institutes, Occasional Paper 7. (1997).

[15] D. Perkins and M. Zimmerman, Empowerment theory, research, and application. The American Journal of Psychology, 23, 569 (1995).

[16] A. Cornwall and K. Brock, Beyond Buzzwords: 'Poverty Reduction,' 'Participation,' and 'Empowerment' in Development Policy. UNRISD, 10 (2005).

[17] A. S. Dimick, Student empowerment in an environmental science classroom: Toward a framework for social justice science education. Science Education, 96, 990 (2012).

[18] S. Tolbert, A. Schindel, and A. J. Rodriguez, Relevance and relational responsibility in justice-oriented science education research. Science Education, 102, 796 (2018).

[19] P. J. McQuillan, Possibilities and Pitfalls: A Comparative Analysis of Student Empowerment. American Educational Research Journal, 42, 639 (2005).

[20] S. Tolbert, N. Snook, C. Knox, and I. Udoinwang, Promoting youth empowerment and social change in/ through school science. Journal for Activist Science \& Teacher Education, 7 $52(2016)$

[21] C. Oyler, and J. Becker, Teaching Beyond the ProgressiveTraditional Dichotomy: Sharing Authority and Sharing Vulnerability. Curriculum Inquiry, 27, 453 (1997).

[22] M. Ross, and V. Otero, Challenging Traditional Assumptions of Secondary Science through the PET Curriculum. PERC Proceedings, 350 (2010). 